\title{
The problem of making optimal decisions on the implementation of economic policy objectives
}

\author{
Revaz Gvelesiani \\ Ivane Javakhishvili Tbilisi State University, Georgia
}

\begin{abstract}
Here write the abstract Optimization of the objectives of economic policy - achieving the maximum result - is possible only through rigorous rationality. On the one hand, it means that during all actions those achievements are to be taken into consideration, which are presented in advance in the form of results. On the other hand, it is necessary to use the evaluation function. It will allow us to evaluate different results according to their characteristics and to act within the desired order.

The evaluation function, together with the decision-making rule, determines which options for using instruments should be given priority. Such functions and rules are primarily focused on the possibility of solving the decision-making problem. Unlike practical situations of decisions preparation, the only decision-maker is taken into consideration. Knowledge of the rule of decision preparation is extremely fragmented. It is unstable in time. This means that information about the value of the instruments is usually incomplete. As for the use of instruments, it is also evaluated incompletely.
\end{abstract}

Keywords: Basic public values, objectives of economic policy, economic interests, decision making theories, subjects of decision-making

\section{Introduction}

The Depending on the freedom granted to the conductor of economic policy, it is possible to distinguish from each other:

a) Discretionary use of the instrument when it is based on the assessment of the overall conductor of economic policy in which situation and how to use it.

b) The use of the instrument by the rule when assessment of the conductor of an economic policy is limited by the fact that, from the very beginning, it is determined by the compulsory legal rule which means in which conditions, what size and length of time it should be used.

The boundary is very variable, which separates discretionary use of the means from each other (which is called a random intervention) and its use according to the rule, which is often referred to as formal flexibility. First of all, we have to deal with the other, when the means is used for the aim of stabilization policy (Streit, 2005).

The freedom of action from the viewpoint of the conductor of economic policy can trigger a temptation to pursue undesirable economic policy. The Parliament may be mistaken to think that passing as much laws as possible is to prove its successful work. It is also possible that the 
executive government is in danger; it may abuse freedom of action under sole discretion and demonstrate its power.

Freedom of action by the decision of the decision-implementer simplifies tacking of economic policy in connection with the short-term outcome. The desire for tacking leads to an increase of interventions, accompanied by an increase of short and long-term impacts. This makes parliamentary control of results harder or more impossible and stimulates the desire for tacking (Streit, 2005).

Freedom of the action by the decision of the decision-implementer makes it possible for the executive government to be influenced by the interest groups. The realization of private interests is easier when the executive government supports them. Such pressure can be avoided only through legislative control.

\section{Methodology}

Both general and specific research methods were used in this article, namely - the methods of analysis, synthesis, induction, deduction, scientific abstraction, comparative analysis, statistics (selection, grouping, observation, dynamics, etc.), static, as well as the methods of experimental evaluation.

\section{Results}

The Random measures make it difficult to plan and orderly coordination of economic policy. On the one hand, it is more difficult to foresee them in advance than the interventions carried out under the rules. On the other hand, losses associated with accidental interventions and control errors appear when there is some time for inspection and coordination of economic policy plans.

Knowledge of management is the prerequisite for success and we often experience the deficit of it. Insufficient knowledge of the interaction of elements of economic policy often leads to enormous risk. The reason for this is excessive trust, which we announce to prediction possibilities of the unknown, delayed impacts.

Several common structural elements are allocated in different form of establishing the rules. The instance of economic policy is acting in accordance with the established rule and/or its ability to act is limited. It is necessary to determine the initiative circumstances (indicators), which obliges the instance and/or grants the right to carry out the necessary action and/or operate within the established limits.

The introduction of such rules, which should arrange possibilities of actions under sole discretion, will fail. That is why knowledge about management is not enough. The discretionary use of the means also leads to the difficulties associated with the knowledge of political problems. If random interventions are possible in these conditions, which will be controlled by the parliament, they will still be problematic. The matter is that the process of delay in instances will be further delayed, and the lawmaking of this scale would be a step-by-step legislative process and would endanger the economic activity of citizens. This would destroy the 
credibility of the legislative authority. Nevertheless, such an ephemeral legislative process is observed in many democratic countries. This explains the fact why all the arguments that support the introduction of standard liabilities are justified. We should also take into consideration that the legislator wants to establish economic policy through the rules. Then, comply with these rules and give strength through ephemeral argumentation.

In cases when there are possibilities to introduce and implement rules, there are several possibilities for a small intervention of economic policy. It is necessary to take into account avoiding of possible losses. Small intervention and "strength of more economic policies" (Eucken, 1959/2004) On the one hand, it means that there is little chance of economic policy, but the risks associated with the accuracy of its control are likely to be decreased. Possibility of predicting the activities of economic policy is increased and in terms of time it is in full compliance with the requirements of market coordination.

When forming the framework conditions of economic order, the more the self-regulation of market coordination is taken into account, the danger of accidental interventions is more decreased. Advantages are given to a consistent, long-term and cautious economic policy. We should take special caution when we try to set the framework conditions for economic order to improve self-regulation of market coordination.

The prescriptive or normative theory of decisions is based on the fact that decision-maker possesses a complete, non-contradictory and stable system. Based on this system, it assesses possible results of the selection process. For the perfect order policy, unequal assessment is required. That is precisely the possibility and the necessity of making optimal choices. As for the descriptive or the positive theory of the decision, it confronts this view with the following opinions: the system of values is not perfect, contradicts and varies; the decision-maker is largely a collective and/or organization that represent a coalition of different interests. Consequently, the formation of a system of values (as a general basis of decision) and the change regarding values takes the form of competition between values of subjective perceptions; Outer influence is added to internal organizational relations during the evaluation of the program and taking decisions. This is done by bureaucratic sub-structures and public opinion; searching of optimal action often does not give us the desired result, so we should always take into consideration the volume of information as well as the limitations of the decision-makers who are required to process this information; So we have to be satisfied with the actions that will ensure the realization of the target at a certain level. Impacts and accompanying outcomes are very vague when searching for the wide and global solution of the problem. Therefore, the advantage is given to the possibility of action that involves minor and easily visible changes compared to the status quo projections (Lindblom, 1958).

According to the prescriptive theory, the problem of decision preparation is resolved by selecting the program. Control of results is consistent with rationality principle, as systematic search for "experience of economic policy". Thus, it is ignored under the descriptive theory, that the decision preparation is the process that considers amendment of initial activity and completion possibility is required. In addition, it does not consider that the implementation of the program within the organization means coercion as well. At this time, there may be a difference between pre-prepared and later realized forms of action. Finally, decision makers often have no motivation to control the results. Thus, there is an assumption that the correctness 
of the choice is doubtful. It is more, the less the difference between the selected and refused choices is estimated. This suspicion pushes the decision-makers to select and evaluate the information chosen by the pre-selected theory (Festinger, 1997) to justify its choice.

Unlike the prescriptive theory, the goals of the decision field and their perceptions are not formed only by the control of results. The control of the results in the descriptive theory is even more different than in the prescriptive theory. The prevailing opinion in prescriptive theory that all phases of choices in case of the decision-making individual (and/or collective) are internalized is only abstraction. It is more realistic to decentralize planning and decision competences that lead to the formation of a network of relations. We should consider its conformities in the process of making choices.

The prescriptive theory of decision making comes from the position of the individual decision makers. Its behavior in the political context resembles representative democracy. It strives to take the function of providing help to everybody in achieving economic welfare.

Democracy's competitiveness theory is the basis of descriptive theory of decision making in economic policy. In this case, the decision-maker is trying to pursue own interests and ideological goals. At the same time, it needs support of voters to take or maintain a political position.

The descriptive theory of economic policy uses micro and macro theoretical approaches. First of all, analysis of production and non-production process regulation practices has micro theoretical orientations (Stigler, 1975), ( Peltzman, 1976). At the same time, existence of such variables in practice that indicate to egotistical interests of decision-makers has been proved (salary structure and bonuses of government and local administration, common economic interests of their members and etc.). This situation should be taken into consideration when determining the behavior of subjects participating in the economic policy.

If we take into account the micro-theoretical results of the decision, some of the abstract provisions for decision making will become clear (implies the actual behavior of individuals and economic groups). In this case, the subject of cognition is "cognitive processes" (Kirsch, 1970) related to solving problems that involve different aspects of perception, reasoning and performance.

During the discussion of macroeconomic approach, the governments (as a collective decision maker) behavior comes to the forefront. In this case the following assumptions are typical:

- When making the choice, the voter accords priority to the achieved level of the country's economic development and applies this logic;

- In economic development problems, it always blames the government;

- The government wants to hold elections for a new term and will try, if there is a risk for its election for a new term, to influence the view of voters on economic development.

The basic structure of such approaches (Frey, 1975) is presented by the majority of scientists as follows: 


\section{BUSINESS, MANAGEMENT \& ECONOMICS}

- The goal of the government is to show that for the realization of the right economic policy it is necessary to fulfil only one condition - its election for a new term;

- The possibility of this depends on the level of popularity of the government in population, which can be presented on the basis of public opinion;

- It should be assumed that between the popularity of the government and the economic variables (which express the level of realization of the objectives of economic policy) there is a relationship (the function of the popularity) that has a clearly expressed face in reality;

- The government is well aware of which tools should be used to influence the economic variables that have the function of popularity;

- The government prefers its popularity in comparison to other goals and if its election is not sufficiently guaranteed for the new term, it reacts to the current situation with the economic policy measures. There is probably some connection between the popularity of government and the use of economic policy instruments.

This variant of the decision-making process explains the behavior of the decision makers, but does not present a lot of decision-makers for observation. Decision-making should be considered as an actor even when it comes to the decision-making body and accordingly to collective decision. We also find such abstractions in the prescriptive theory. In terms of determining behavior in economic policy, they are less important than in the case of optimal decision-making. From the motivation of understanding the problems of economic policy, only the analysis of the factors (changes) of the government's popularity are analyzed. They hinder the realization of party and ideological goals. This means that setting of ideological goals and attemptions to implement them make sense when the popularity gives a new chance of election for a new term (Frey\&Schneider, 1979).

Theoretical models of economic policy only proved that if the government still has little chance of election for a new term, it is trying to carry out an expansionary policy in the election period (Paldam, 1979). There is doubt about the results, even when the model is oriented to the theory of economic policy. The problem is that the event explained by macro-theoretic aspect is weakly and inconclusively substantiated (Stigler, 1973), ( Locksley, 1980). In terms of supply policy, the focus on private interests is not stipulated, while they are the subject of observation. As for the demand aspect (popularity function), the critical variables of unemployment and inflation indicators are perceived comprehensively only in the best possible way by the voters and positively assessed.

\section{Conclusion}

In the theoretical models of economic policy, it is not stipulated yet what kind of influence the ruling party, interests groups and state bureaucracy have on making decisions for their own interests. The value system, which is essential in terms of decisions, is only partially revealed. At the same time, it does not mean that the social welfare function is also partially represented. On the contrary, here it comes to the purpose of the goal, which is important for decision- 
makers. Consistent analysis is subject to certain goals. The quality of their realization is confirmed by the explanations that are fulfilled for the aim of acquiring a change of popularity. According to such approaches, the quantified goals related to order policy are maximally implemented and subjected to control.

The level of the economic policy program election and its assessment is only shown by the result. Priorities of the decision-makers are expressed in its reactions. At any rate, it is possible to assume that realized ideas of the decision maker are exposed to certain intensities. It is determined by the aspiration of the decision-maker, which appears in the implementation of the goals of economic policy and the dose of measures. In this case the rule of decision making is determined by the election of the subject for a new term. For this it is not necessary to have the maximum number of votes, as it is required by classical models of party competition. It is only necessary that the chances of electing for a new term are sufficiently large. Consequently, complaints related to success of programs in economic policy are limited.

\section{References:}

[1] Gvelesiani R. (2017), The problem of considering possible consequences of the consistent reforms in the economic-political decisions, Review of Business research (RBR), Vol.17, pp.19-24.

[2] Gvelesiani R. (2018), The Problem of Compatibility of Market Liberty with Social Equality, European journal of business Research (EJBR), Vol. 18, pp.39-44.

[3] Gvelesiani R., (2017), Economic-Political Decision-making empirically and taking into account the analytically applicable and estimation subjected changes, Journal "New Economist," (in Georgian) Vol. №1, pp.16-21.

[4] Gvelesiani R., (2018), Relation of the Concept of Social Market Economics with Key Public Values, Journal (in Georgian). "Economist," №3, Vol. XIV, pp.26-36.

[5] Gvelesiani R., Gogorishvili I, (2015), Problems of Economic-Political Decision-Making and Their Overcoming Opportunities, Journal "Economics and Business," (in Georgian) Volume VIII, pp. 34-45.

[6] Lindblom, CH. E. (1958), Policy Analysis, American Economic Review, Vol.48, pp.298312.

[7] Paldam, M. (1979), Is there an Electional Cycle? - A Comparative Study of National Accounts, Scandinavian Journal of Economics, Vol. 81, pp.323-342.

[8] Peltzman, S. (1976), Toward a More General Theory of Regulation, Journal of Law and Economics, Vol.19, pp. 211-240.

[9] Stigler, G.J. (1973), General Economic Conditions and National Elections, American Economic Review, Vol. 63, pp.160-167.

[10] Festinger, L. (1957), A Theory of Cognitive Dissonance, Neudruck, Stanford.

[11]Frey, B.S. (1975), Eine Einschaetzung der Neuen Politischen Oekonomie der siebziger Jahre. Zeitschrift fuer die gesamte Staatswissenschaft, pp. 697-718. 


\section{$2^{\text {nd }}$ International Conference on BUSINESS, MANAGEMENT \& ECONOMICS}

[12]Frey, B.S. und F. Schneider (1979), An Economeric Model with an Endrogenous Government Sector, Public Choice 34, pp.29-43.

[13] Kirsch, W. (1970), entscheidungsprozesse (Bd. 1: Verhaltenswissenschaftliche Ansaetze der Entscheidungstheorie), Wiesbaden, p.68.

[14]Locksley, G. (1980), The Political Business Cycle: Alternative Interpretations: inp. Whiteley (Hrsg.): Models of Political Economy, London, Beverly Hills, pp.177-198

[15] Stigler, G. J. (1975), The Citizen and the State - Essays on Regulation, Chicago und London.

[16] Streit, M. E. (2005), Theorie der Wirtschaftspolitik, Auflage, Stuttgart, p.322; p. 323; pp.379-380.

[17] Tinbergen, J. (1964), Economic Policy - Principles and Design, reprint, Amsterdam.

[18] Gvelesiani R., Gogorishvili I. (2018), Decision-making Technology in Economic Policy (in Georgian), Tbilisi, pp.85-86. 